\title{
A Review on Lithium-Ion Battery Separators towards Enhanced Safety Performances and Modelling Approaches
}

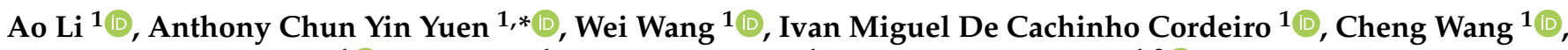 \\ Timothy Bo Yuan Chen ${ }^{1}{ }^{\mathbb{C}}$, Jin Zhang ${ }^{1}$, Qing Nian Chan ${ }^{1}$ and Guan Heng Yeoh ${ }^{1,2}{ }^{\mathbb{C}}$ \\ 1 School of Mechanical and Manufacturing Engineering, University of New South Wales, \\ Sydney, NSW 2052, Australia; ao.li@unsw.edu.au (A.L.); wei.wang15@unsw.edu.au (W.W.); \\ i.decachinhocordeiro@unsw.edu.au (I.M.D.C.C.); c.wang@unsw.edu.au (C.W.); \\ timothy.chen@unsw.edu.au (T.B.Y.C.); jin.zhang6@unsw.edu.au (J.Z.); qing.chan@unsw.edu.au (Q.N.C.); \\ g.yeoh@unsw.edu.au (G.H.Y.) \\ 2 Australian Nuclear Science and Technology Organization (ANSTO), Locked Bag 2001, Kirrawee DC, \\ NSW 2232, Australia \\ * Correspondence: c.y.yuen@unsw.edu.au
}

Citation: Li, A.; Yuen, A.C.Y.; Wang, W.; De Cachinho Cordeiro, I.M.; Wang, C.; Chen, T.B.Y.; Zhang, J.; Chan, Q.N.; Yeoh, G.H. A Review on Lithium-Ion Battery Separators towards Enhanced Safety Performances and Modelling Approaches. Molecules 2021, 26, 478. https://doi.org/10.3390/ molecules26020478

Academic Editor: Gaëlle Fontaine

Received: 14 December 2020

Accepted: 14 January 2021

Published: 18 January 2021

Publisher's Note: MDPI stays neutral with regard to jurisdictional claims in published maps and institutional affiliations.

Copyright: (C) 2021 by the authors. Licensee MDPI, Basel, Switzerland. This article is an open access article distributed under the terms and conditions of the Creative Commons Attribution (CC BY) license (https:/ / creativecommons.org/licenses/by/ $4.0 /)$.

\begin{abstract}
In recent years, the applications of lithium-ion batteries have emerged promptly owing to its widespread use in portable electronics and electric vehicles. Nevertheless, the safety of the battery systems has always been a global concern for the end-users. The separator is an indispensable part of lithium-ion batteries since it functions as a physical barrier for the electrode as well as an electrolyte reservoir for ionic transport. The properties of separators have direct influences on the performance of lithium-ion batteries, therefore the separators play an important role in the battery safety issue. With the rapid developments of applied materials, there have been extensive efforts to utilize these new materials as battery separators with enhanced electrical, fire, and explosion prevention performances. In this review, we aim to deliver an overview of recent advancements in numerical models on battery separators. Moreover, we summarize the physical properties of separators and benchmark selective key performance indicators. A broad picture of recent simulation studies on separators is given and a brief outlook for the future directions is also proposed.
\end{abstract}

Keywords: lithium-ion battery; separator; numerical modelling; battery safety

\section{Introduction}

Pioneered by Yoshino in 1985 [1,2], lithium-ion (Li-ion) batteries have been commercialized and used ever since in the industry as an alternative source of energy. It is usually applied as an energy storage reservoir for renewable energies and commonly used in portable electronics and electric vehicles. Nonetheless, a Li-ion battery is less thermally stable in comparison with other battery systems. This has caused a significant amount of battery fires in recent years, which occurred in mobile phones, electric vehicles, and airplanes [3-6]. The Li-ion battery separator is one of the crucial factors affecting fire safety performance since it directly contributes to the thermal stability of the entire battery system.

As one of the most important components in Li-ion batteries, the separator is placed between the anode and cathode [7]. The schematic diagram about a common separator applied in Li-ion batteries is shown in Figure 1, with the function of preventing physical contact between electrodes while serving as the electrolyte reservoir to enable ionic transport. There are no direct cell reactions in the separator, but the structure and properties of the separator play an essential role in determining the battery performance, including cycle life, safety, energy density, and power density, through influencing the cell kinetics [8]. A wide variety of factors should be considered while selecting appropriate separators for use in Li-ion batteries. Table 1 summarizes the general requirements that should be considered for Li-ion battery separators, and the detailed discussion has been provided 
by previous studies, such as development of membrane separators by Lee et al. [8], production process of separators by Deimede et al. [9], characterization and performance evaluation of separators by Lagadec et al. [10], and so on. These early reviews focused on the characterization methods for separator properties and manufacturing techniques for separators through experimental methods. Moreover, the application of the separator increases electrical resistance and takes up limited space inside the battery, which has a negative impact on battery performance. Therefore, reasonable utilization of a separator is of vital importance to improving the battery performance, which includes energy density, cycle life, power density, and fire safety.

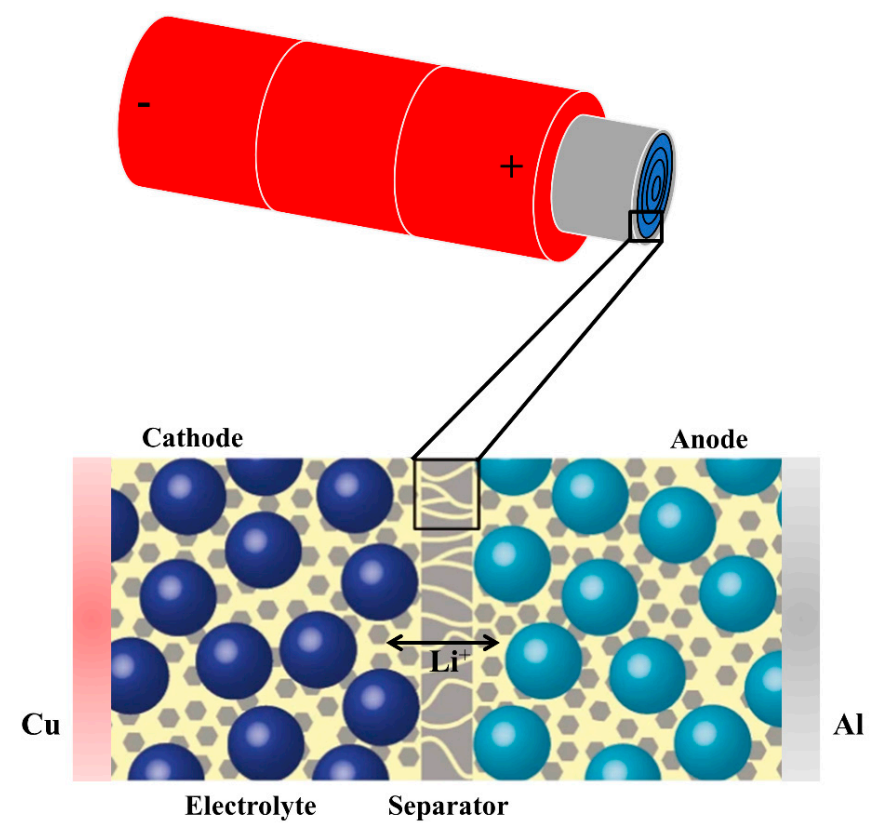

Figure 1. Schematic image of a separator in cylindrical Li-ion battery cell and a zoomed-in crosssection of the layered structure.

Table 1. General requirements for separators used in Li-ion batteries [8].

\begin{tabular}{ll}
\hline Parameter & Requirement \\
\hline Chemical and electrochemical stabilities & Stable for a long period of time \\
Wettability & Wet out quickly and completely \\
Mechanical property & $>1000 \mathrm{~kg} \cdot \mathrm{cm}^{-1}(98.06 \mathrm{MPa})$ \\
Thickness & $20-25 \mu \mathrm{m}$ \\
Pore size & $<1 \mu \mathrm{m}$ \\
Porosity & $40-60 \%$ \\
Permeability (Gurley) & $<0.025 \mathrm{~s} \cdot \mu \mathrm{m}^{-1}$ \\
Dimensional stability & No curl up and lay flat \\
Thermal stability & $<5 \%$ shrinkage after 60 min at $90^{\circ} \mathrm{C}$ \\
Shutdown & Effectively shut down the battery at \\
& elevated temperatures \\
\hline
\end{tabular}

In view of battery safety, the separator must be able to act as a blocking interface between the electrodes when an internal short circuit occurs, so that the thermal runaway is avoided [11]. Chemical and thermal stability, as well as shutdown function at the set temperature, should be the requirement for the separator. Considering the material price, current technology, and the trade-off relationship of the above properties, a comprehensive evaluation of the separator properties is required for separator selection. In order to improve the performance of separators and enhance the safety of Li-ion batteries, researchers have thus performed a lot of research work in recent years [12-14]. Furthermore, numerical modelling on the design and test of separators for improving battery abuse tolerance and performance 
is deemed a practical compromise in optimizing the separator in future battery systems. Compared with the experimental investigation on separators, numerical modelling is treated as an efficient and economic tool for the study of separators. Both the separator material properties and the various performances of the separator are able to be simulated and predicted by numerical models. In this paper, the current numerical studies of separators will be reviewed in terms of mathematical models, finite element analysis (FEA), and computational fluid dynamic (CFD) models, and molecular dynamic (MD) models. From the perspective of numerical study, we describe the separator performance based on its influence on the battery performance, including microstructure of separators, stress analysis for the separators, thermal and ion transport of separators, as well as degradation process of separators. Moreover, the relationship between separator properties and battery safety will be discussed based on the separator shutdown and separator breakdown. Based on this review, future research directions on the Li-ion battery separators will be discussed in detail.

\section{Numerical Study of Separators}

Separators must be chemically and electrochemically stable to the electrolyte and electrode materials in Li-ion batteries since the separator itself does not participate in any cell reactions. As a critical component inside Li-ion batteries under strongly oxidizing and reducing conditions when the battery is fully discharged and charged, separators should also be mechanically strong to withstand the high tension during the battery assembly operation. In terms of the properties and performances of the separator, related numerical studies of battery fire safety can be divided into separator shutdown and separator breakdown, which are reviewed in this section.

\subsection{Numerical Methods}

With the development of computer science, numerical simulations are gradually applied in many assessments of separator safety designs. Compared to standard experiments, numerical simulation validates experiment results with less physical resources and also reveals in-depth key performance parameters including temperature, pressure, electrochemical properties. Furthermore, we are able to visualize the battery system internally to effectively diagnose the problems that may lead to potential battery failures. The development of numerical battery models has facilitated better understanding of the underlying principles of the battery circuit and its associated influence towards the ambient environment. Figure 2 summarizes the reviewed numerical studies in this paper.

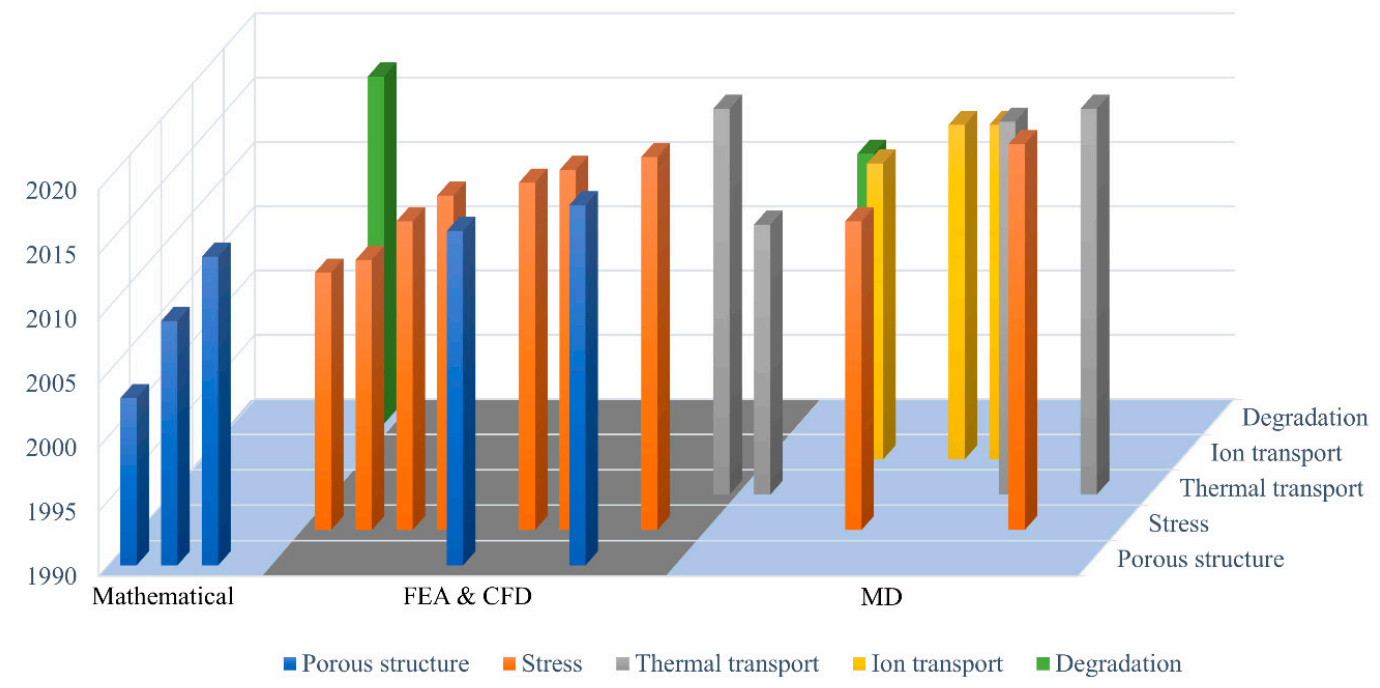

Figure 2. Summary of the reviewed papers for separators categorized by numerical methods and performances.

Mathematical models have been widely used in the battery property investigation and battery working procedure [15-17]. The development of a detailed mathematical model 
is important to design and optimize the batteries. Simulation results provide intuitive data on the performance of the battery. A suitable mathematical model can describe a few parameters which are not known experimentally and regulate parameter adjustment. For example, the direct experimental data for tortuosity or liquid-phase transport resistance is lacking, which can be simulated from mathematical models $[18,19]$.

Finite Element Analysis (FEA) theories and methods originate from the need to solve complex elasticity and structural analysis problems in engineering [20]. This method has been developed and applied in studying the mechanical properties, and many FEA packages such as ABAQUS, LS-DYNA, RADIOSS were used to model the material structure. Computation fluid dynamics (CFD) is a practical tool to study different thermal fluid dynamic parameters and simulate multiple physics fields [21-23], and CFD makes it possible to use the equations governing a fluid motion for an extensive range of complex situations, providing both insight and quantitative predictions. CFD simulation can provide detailed information about the electrical and thermal field inside the battery that is often difficult to be assessed by experimental means. Model-based investigations promote theoretical understanding of battery physics beyond what is possible from experiments only.

Molecular dynamics (MD) simulations have been applied to understand the properties at the molecular-level and design chemical structures with high performance. There are variations of MD simulation models utilizing different chemical force-field based on their characterizing phenomena, for instance, pyrolysis [24], nucleation [25], material thermal/electrical properties [26], and so on. Moreover, MD simulations are used to predict the chemical interactions between different materials and understand numerous membrane properties. Table 2 summarized the numerical studies associated with separators, which are applied with numerical simulations, including mathematical models, FEA and CFD simulations, MD simulations, and so on.

Table 2. The summary of the reviewed numerical studies for separators with model parameters.

\begin{tabular}{|c|c|c|c|}
\hline Numerical Method & Model Parameters & Year & Ref \\
\hline \multirow{4}{*}{ Mathematical model } & Bruggeman exponent $\alpha$ & 2003 & [27] \\
\hline & Tortuosity & 2009 & {$[19]$} \\
\hline & Distance map, spatial distribution map, and histogram & 2014 & {$[28]$} \\
\hline & Capacity loss, temperatures, and SOC & 2017 & [29] \\
\hline \multirow{10}{*}{ FEA and CFD } & $\begin{array}{l}\text { Packing pattern, thickness variation, stress, } \\
\text { and viscoelastic relaxation }\end{array}$ & 2010 & {$[30]$} \\
\hline & Stress distribution, thermal effect, friction, particle radius, separator thickness & 2011 & {$[31]$} \\
\hline & Principal stresses and Von Mises stress & 2014 & [32] \\
\hline & Stress-strain curves and force-displacement curves & 2016 & [33] \\
\hline & $\begin{array}{c}\text { Porosity } \varepsilon \text {, tortuosity } \tau \text {, and effective } \\
\text { transport coefficient } \delta\end{array}$ & 2016 & {$[34]$} \\
\hline & Stress-strain curves, deformed shapes, and pores diameter & 2017 & {$[35]$} \\
\hline & Strain, stress, node angle, voltage drop, and C-rate & 2018 & {$[36]$} \\
\hline & $\begin{array}{l}\text { Porosity, TP tortuosity, separator thickness, } \\
\text { and connectivity density }\end{array}$ & 2018 & [37] \\
\hline & Stress-strain curves & 2019 & {$[38]$} \\
\hline & $\begin{array}{l}\text { Thickness, porosity, energy density, heat generation rate, temperature, thermal } \\
\text { conductivity, and heat capacity }\end{array}$ & 2020 & [39] \\
\hline \multirow{9}{*}{ MD } & Tip temperature, current density, and tip aspect ratio & 2011 & {$[40]$} \\
\hline & Li density, SEI thickness, component ratio & 2011 & {$[41]$} \\
\hline & Free energy, radial distribution functions, and proton transfer coordinate & 2013 & {$[42]$} \\
\hline & Young's modulus and density & 2014 & {$[43]$} \\
\hline & Proton concentration (i.e., $\mathrm{C}_{\mathrm{H}+}$ ) & 2016 & {$[44]$} \\
\hline & $\begin{array}{l}\text { Proton conductivity and ion exchange } \\
\text { capacity value }\end{array}$ & 2016 & {$[45]$} \\
\hline & Temperature, density, heat flux, and thermal conductivity & 2019 & {$[46]$} \\
\hline & Young's modulus & 2020 & [47] \\
\hline & Interfacial thermal conductance & 2020 & {$[48]$} \\
\hline
\end{tabular}




\subsection{Separator Shutdown}

As shown in Figure 1, the location of the separator decides its primary function is to separate the anode and the cathode. The mechanical properties of separators are therefore very important for maintaining separation and Li-ion battery safety. Polyethylene (PE), polypropylene (PP), and $\mathrm{PE} / \mathrm{PP}$ separators with pore sizes in the range of micrometres have been commercialized and widely used in Li-ion battery technology [49]. These microporous separators play a protective role during cell abuse. For example, if the temperature of the battery cell rises abnormally, separator shutdown occurs, which indicates that separators can provide a margin of safety to the device instead of leading to thermal runaway caused by the direct contact of electrodes. Numerical simulations can be carried out to study the microstructure and mechanical properties of the separator and to predict battery safety.

\subsubsection{Porous Structure}

Microporous membranes are normally characterized by pore sizes in the micrometre scale and are mainly manufactured based on polyolefin materials, such as PE, PP, and their blends such as PE-PP, as they afford both excellent chemical stability and mechanical properties. High-density polyethylene (HDPE) and ultrahigh molecular polyethylene (UHMWPE) are also used for preparing microporous membranes [50]. Therefore, numerical study as a simplified analysis has been employed to evaluate the effect of separators in practice [16]. In mathematical modelling, the following empirical equation has been widely used.

$$
R_{s}=\varepsilon^{-\alpha} \cdot R_{0}
$$

where $R_{S}$ is the resistance of the separator filled with liquid electrolyte, $R_{0}$ is the resistance of the native liquid electrolyte, $\varepsilon$ is the void volume fraction in a separator, and $\alpha$ is the Bruggeman exponent. Separator morphology plays an important role in battery design and battery safety; therefore, numerical studies can provide better justification for the morphological parameters of separators for design and optimization.

Patel et al. [27] demonstrated models of porous networks to investigate the influence of particle shape and overall porosity on the liquid phase conductivity inside electrodes or separators used for Li-ion batteries. These models demonstrate that for batteries with high-rate performance, spherical or slightly prolate ellipsoidal particles should be preferred. Porous networks based on other particle morphologies however increase the tortuous path for ionic conductivity and result in either a significant increase of the exponent $\alpha$, or a complete deviation from the power law.

Thorat et al. [19] applied a mathematical model for an empirical relationship between porosity and the tortuosity of the porous structures. They concluded that the tortuositydependent mass transport resistance in porous separators and electrodes is significantly higher than that predicted by the often-used Bruggeman relationship. Moreover, ChenWiegart et al. [28] proposed a distance propagation method for calculating tortuosity with relatively low computation time from three-dimensional (3D) tomographic data.

Lagadec et al. [34] built an electrolyte-soaked separator model and studied the influences of the separator microstructure on the battery performance. The porosity $\varepsilon$ and tortuosity $\tau$ of the polyethylene separators directly influence the transport properties (the concentration-dependent electrolyte $D_{l}$ and the concentration-dependent electrolyte $\sigma_{l}$, calculated according to Nyman et al. [51]). The electrolyte conductivity decreased with the separator microstructure, and the potential drop can be thereby increased across the electrolyte-soaked separator. Based on their simulations, it is clearly illustrated that increasing the electrolyte conductivity and the transference number in separator membranes can improve the Li-ion battery performance, particularly at high current rates. Lagadec et al. [37] delivered an analysis of tomographic data of commercial separators. They demonstrated the extent to which Li-ion concentration gradients can be induced or smoothed by the separator structure. This is linked to the pore space connectivity, i.e., a parameter that can be determined by topological or network-based analysis of separators. 


\subsubsection{Stress Analysis}

It is well recognized by the Li-ion battery community that stress plays an essential role in the performance of the separator. To enhance the battery separator's performance, the stresses upon the separator in situ must be fully understood. Young's modulus, which is a physical quantity parameter evaluating the anti-deformability of elastic materials subjected to external force, is applied to evaluate the mechanical performance of separators. In view of battery safety for Li-ion batteries, a larger elastic modulus enables the separator to sustain internal or external pressure and local stress. In order to evaluate the intercalation and thermal mismatch induced stresses in the separator, multi-scale multi-physics models have been proposed and developed [30,31,52]. Testing the mechanical properties of a separator in situ in a battery is one of the tasks in improving the performance of battery separators [53]. For an isotropic material, the mechanical stress has a constitutive relationship for the strain, which is given as [30]:

$$
\varepsilon_{i j}=\frac{1}{E}\left((1+v) \sigma_{i j}-v \sigma_{k k} \delta_{i j}\right)
$$

where $\varepsilon_{i j}$ is the strain component, $E$ is Young's modulus, $v$ is the Poisson's ratio of the material, and $\delta_{i j}$ is the Dirac delta function. Moreover, with the understanding of the mechanical properties of separators, battery safety performance can be estimated and optimized. Table 3 summarizes the numerical stress analysis results in this section.

Table 3. Stress analysis summary for separators used in Li-ion batteries.

\begin{tabular}{|c|c|c|c|c|}
\hline Materials & Young's Modulus (GPa) & Poisson's Ratio & Average Strain (\%) & Ref. \\
\hline $\begin{array}{c}\text { Polyolefin } \\
\text { Poly(vinylidene fluoride) (PVDF) }\end{array}$ & $\begin{array}{c}0.2 \\
0.05\end{array}$ & 0.35 & $\begin{array}{l}-0.14 \\
-0.035\end{array}$ & [30] \\
\hline A homogeneous solid medium & 0.5 & 0.35 & -0.40 & [31] \\
\hline PP separator Celgard 2400 & 0.1 & - & - & [32] \\
\hline $\begin{array}{l}\text { PE microstructure } \\
\text { PP microstructure }\end{array}$ & $\begin{array}{l}1.2 \\
1.5\end{array}$ & 0 & -0.40 & [36] \\
\hline PP & $\begin{array}{c}\text { In vacuum/In DMC } \\
\text { Crystalline fiber: } 43.4 / 46.5 \\
\text { Infinitely long chain fiber: } \\
0.66 / 0.07 \\
\text { Finite chain fiber: } 0.29 / 0.01\end{array}$ & - & - & [43] \\
\hline Cellulose/lignin & $\begin{array}{c}\text { Dry/Wet } \\
\text { Pure cellu: } 3.38 / 2.50 \\
\text { Lignin 2.5\%: } 3.90 / 3.58 \\
\text { Lignin 5\%: } 4.10 / 3.25 \\
\text { Lignin 7.5\%: } 4.23 / 2.98 \\
\text { Lignin 10\%: } 4.78 / 2.88\end{array}$ & - & - & [47] \\
\hline
\end{tabular}

Xiao et al. [30] developed a multi-physics, multi-scale model of a lithium-ion battery cell by using COMSOL. Their simulation results illustrate that the stress is affected by Young's modulus of the separator, electrode particle size, separator wrapping patterns, and the pressure of the cell, and the local strain at the indented areas was much higher than the nominal strain of the separator.

Shi et al. [31] investigated the influences of some adjustable design parameters, including the effective friction, electrode particle radii, and thickness of the separator, on the stresses in the separator. It is concluded that the maximum Von Mises stress increased as increasing the thickness of the separator and the effective frictions between the separator and its adjacent electrodes. The stress analysis showed that the maximum stress in the separator always emerged at the area around the inner corner of the separator. In this case, the cell voltage at $4.2 \mathrm{~V}$ was assumed to be fully charged. The schematic of the structure represents the macro-scale $2 \mathrm{D}$ model with separator thickness of $25 \mu \mathrm{m}$ and 
anode thickness of $45 \mu \mathrm{m}$. When the Li-ion battery was fully charged, the maximum stress was wrapped around the edge of the anode, as shown in Figure 3. In addition, with the same volume fractions of active materials, the particle radii had a negligible effect on the stress in the separator.
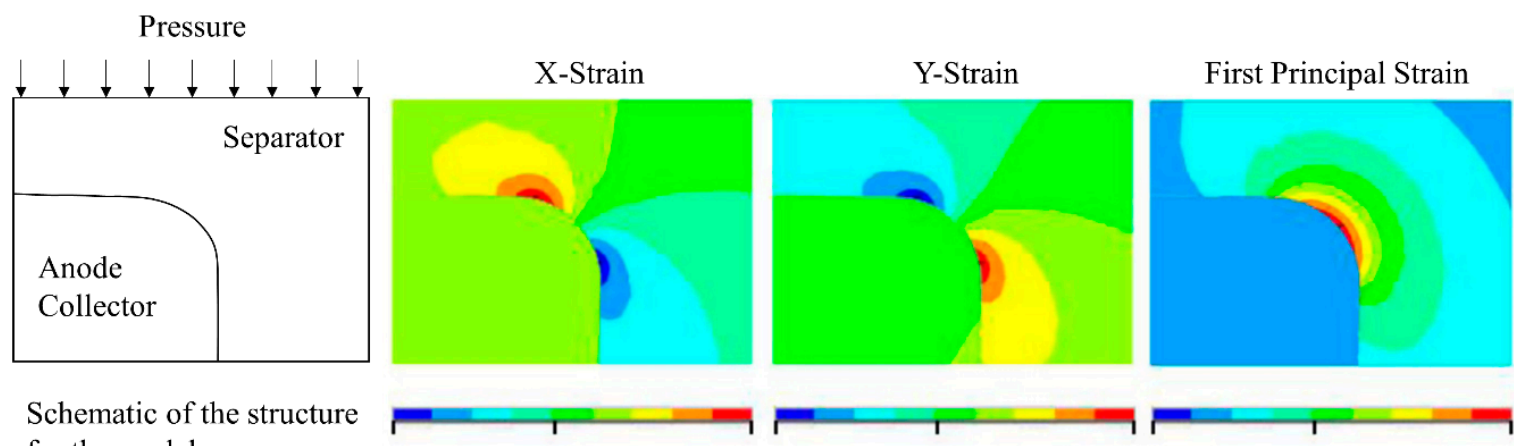

for the model

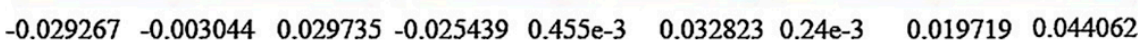

Figure 3. Schematic and contours of strain [ $\left.\mathrm{m} \mathrm{m}^{-1}\right]$ components in the separator near the corner [31].

A multi-physics model was built by Wu et al. [32] to analyze the stress in the PP separator via COMSOL. The results showed that the effects of the intercalation and thermal expansion are coupled summations and hence must be considered concurrently. The type of the constitutive relationship of the separator affects the stress values. The calculated stresses in the separator with a viscoelastic material law were about a half of that estimated with an elastic law.

A finite element model of PE separator was developed in LSDYNA by Zhang et al. [33] based on the uniaxial tensile and through-thickness compression test data. The model succeeded in predicting the response of PE separator under punch tests with different sizes of punch head, including 1 inch $(25.4 \mathrm{~mm}), 1 / 2$ inch $(12.6 \mathrm{~mm}), 1 / 4$ inch $(6.35 \mathrm{~mm})$, and $1 / 8$ inch $(3.175 \mathrm{~mm})$, which is shown in Figure 4 . The model also correctly predicted the effect of anisotropic material on the shape and curvature of deformation in two planes of anisotropy. Furthermore, the anisotropic mechanical behaviour of the material can be analyzed by FEA models as well. Bulla et al. [54] developed a model to predict the anisotropic response of the PE separator due to deformation and failure by combining the novel failure criterion with Hill's yield surface and a Swift-Voce hardening rule.
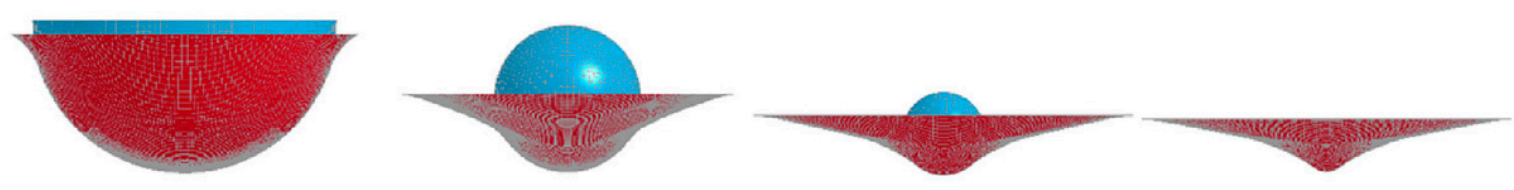

Figure 4. Punch test simulation with different punch sizes [33].

An image-based microstructure representative volume element (RVE) modelling method was applied by Xu et al. [35], which facilitates the understanding of the separators' complex macro mechanical behaviour as a result of microstructural features. The proposed method successfully captures the anisotropic behaviour of the separator under tensile test and provides insights into microstructure deformation, such as the growth of voids. In this study, the imaging processing method and finite element simulation are successfully coupled to analyze the stress-strain relation of battery separators. Furthermore, Xu et al. [55] developed a microstructure modelling method to investigate the deformation patterns of the battery separator. Based on their results, the reason why the separator film turns transparent has two folds was explained. One is the material-level instability, and the other is the structure-level instability.

Lagadec et al. [36] characterized how the microstructural properties (including porosity, tortuosity, and permeability) of the separators change as a function of compressive 
strain and predicted the influence of these changes on the Li-ion transport through the separator by mechanical simulations. They also concluded that a given compressive strain negatively impacts the microstructure of PE separator more than that of a PP separator, because PE has a lower Young's modulus, smaller pore sizes, and a more isotropic structure.

$\mathrm{Xu}$ and Bae [38] proposed a stochastic reconstruction algorithm to generate random but statistically equivalent 3D microstructure models for mechanical property analysis and uncertainty quantification. The proposed modelling method provides a tool to establish the "microstructure-property" relation, which can be considered as important separator design variables.

In addition, from the molecular level, investigations of atomic interactions provide a deep understanding of the stress of separators in Li-ion batteries. Yan et al. [43] mapped the separator microstructure into discrete atomistic models of bulk crystalline phases and oriented amorphous nanofibers at different conditions such as in vacuum, water, and dimethyl carbonate (DMC) by using MD (See Figure 5). The mechanical responses of a porous PP separator in different media were found, which indicates that DMC can penetrate into the amorphous nanofiber and result in Young's modulus reduction to one-tenth of its original value, while a polar solvent (e.g., water) can increase Young's modulus by slightly squeezing the amorphous fibre due to the repulsive interaction.

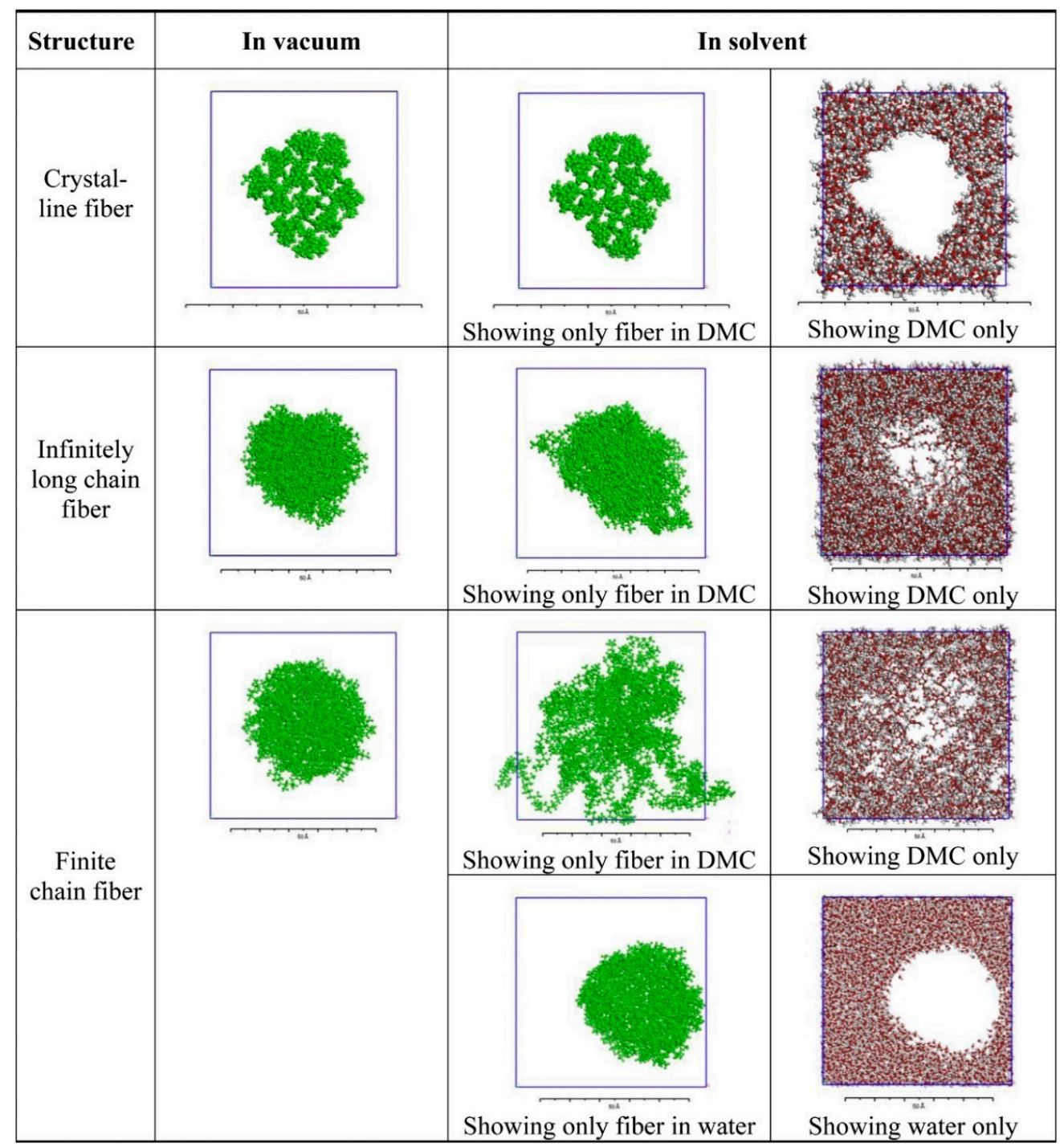

Figure 5. Relaxed structure for crystalline fibre, infinitely long chain fibre and finite chain fibre in vacuum, in DMC, and in water at zero strain [43]. 
Xie et al. [47] successfully applied molecular simulation to unveil that the weakening of cellulose separator submerged in the electrolyte results from the deformed cellulose amorphous region and the promoting effect of adding lignin. The addition of lignin generates new hydrogen bonds between the cellulose and lignin molecules and subsequently form a larger fibrous network. The weakening phenomenon of cellulose separator immersed in the electrolyte is mainly caused by the deformation of the cellulose amorphous region, shown in Figure 6.

(a)

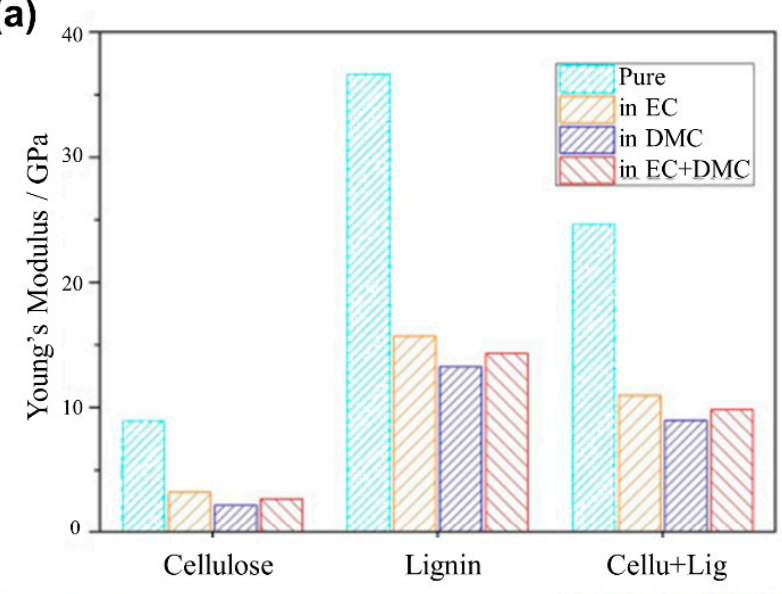

(b)

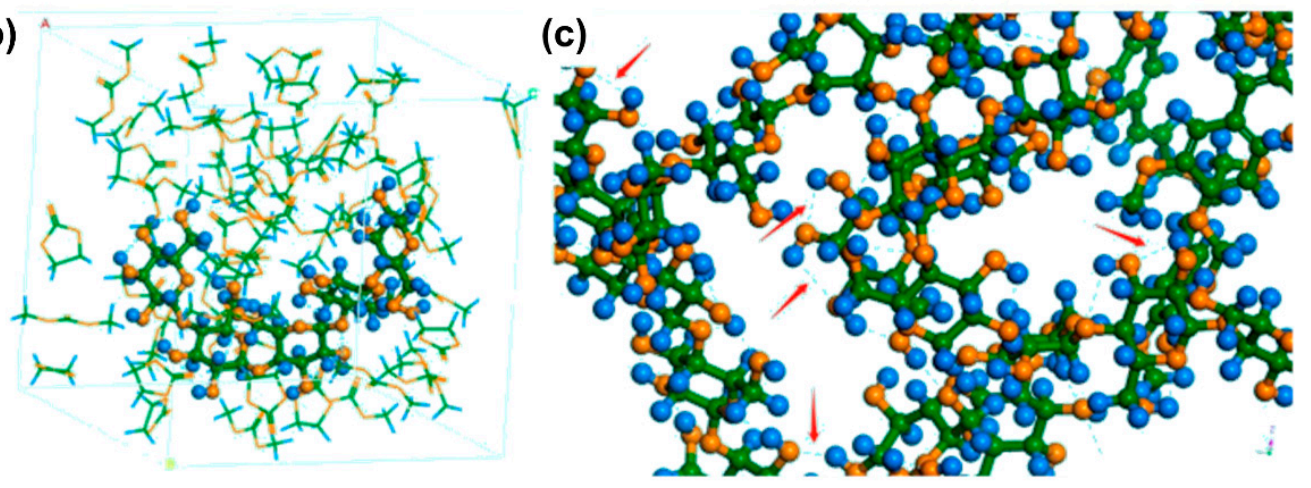

Figure 6. Simulation results from Xie et al. [47] (a) simulated Young's modulus of molecular models under different environments, and distinct details in blended models: (b) deformed cellulose amorphous model in electrolyte solvents and (c) generated hydrogen bonds between cellulose and lignin molecules.

\subsection{Separator Breakdown}

During the battery working progress, it is possible that due to thermal inertia the temperature can continue to rise until the separator would melt and short the electrodes, leading to violent reactions and heat generation [56]. This phenomenon is called separator breakdown, which is one step of the Li-ion battery thermal runaway process. Therefore, the thermal properties of separators have a strong influence on battery safety. Numerical studies in this field can provide a better understanding of the separator breakdown mechanism and give reliable prediction results. Other related performances such as ion transport and the solid electrolyte interphase (SEI) degradation can be modelled as well by numerical methods.

\subsubsection{Thermal Transport}

As mentioned in the Introduction, the separator acts as an essential role in improving battery safety performance. Low thermal transport in Li-ion cells and battery packs has been widely recognized as a critical technological concern that limits the use of Li-ion batteries $[49,57,58]$. Therefore, the focus for the current development of advanced Li-ion 
battery separators is to enhance the safety performance of the separator and/or facilitate the ionic flow through the separator during battery operation.

Standard MD simulation studies thermal transport and heat conduction across the molecular interfaces at the given length-scales ( a few nms). For example, MD simulations have been employed to model thermal transport across a variety of material pairs such as graphene-semiconductor heterostructures [59], $\mathrm{Si} / \mathrm{Ge}$ interfaces [60], silicene/silica interfaces [61], graphene/phosphorene interfaces [62], etc. The thermal conductivity study on the electrodes and solid electrolytes have also been carried out, including equilibrium molecular dynamics [63] and nonequilibrium molecular dynamics simulation method [64].

Parviainen et al. [40] developed a new model, based on an existing MD code, to include resistive heating and electronic thermal conduction. The model accounts for dynamic changes of both tip geometry and temperature and gives an accurate and detailed view of the temperature development, including the temperature gradient in tips. For nanosized field emitters, it is critical to account for finite-size effects since both electric and thermal conductivity have a strong size dependence at this scale (height $13.1 \mathrm{~nm}$ and diameter $2 \mathrm{~nm}$ ).

Non-equilibrium MD simulations were performed by Kawagoe et al. [46] on bulk amorphous polyacrylic acid with three polymer chain lengths to investigate the molecular mechanism of thermal energy transfer in heat conduction. The simulation results showed that the dominant mechanism of thermal energy transfer in polyacrylic acid (PAA) was intramolecular interaction. Consequently, the intramolecular interaction caused the thermal conductivity to increase as the polymer chain length elongated, which also increased the total thermal conductivity. The relation between thermal conductivity and the polymer chain length results in a saturation curve, which will lead to the characterization of thermal energy transfer in more complicated materials such as the layer-by-layer membranes.

Dhakane et al. [48] applied MD simulations for the calculation of thermal conductance across the cathode-separator interface with the interface force field in Figure 7. It is shown that molecular bridging at the interface results in up to $250 \%$ improvement in interfacial thermal conductance for the 3-Aminopropyl triethoxysilane (APTES) case. These results quantify the crucial role of the cathode-separator interface on thermal transport within the Li-ion cell, as well as the potential improvement in interfacial thermal transport by molecular bridging.
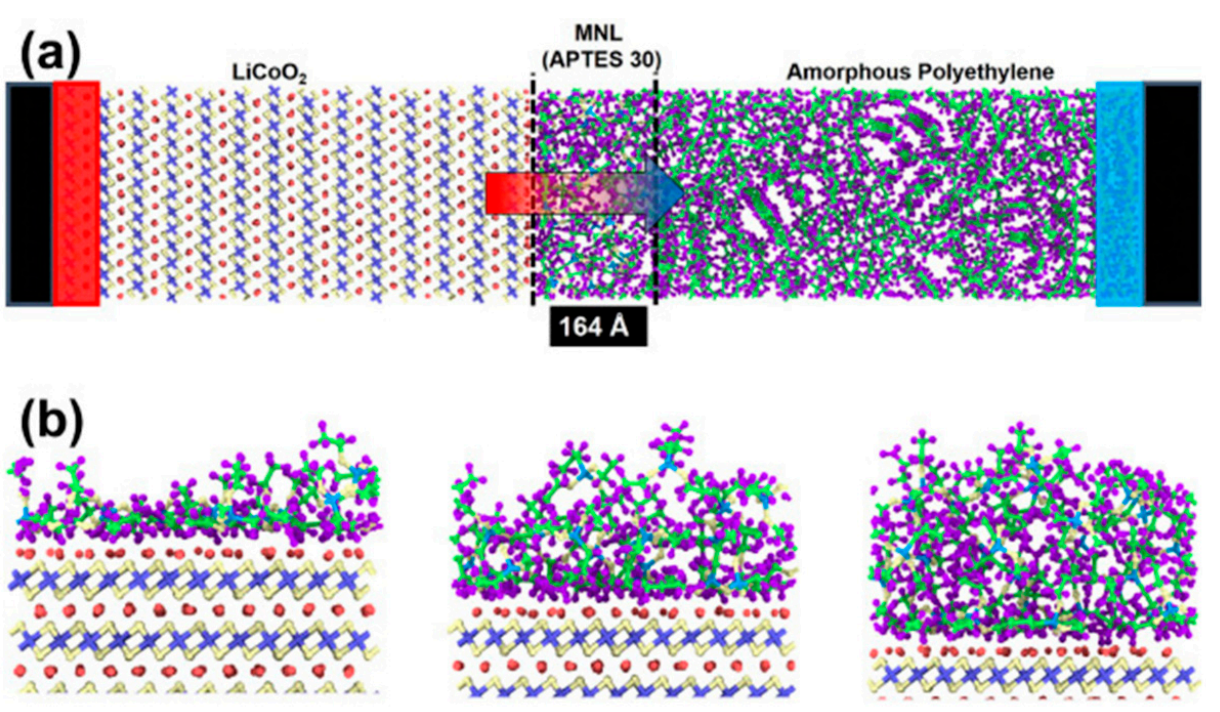

Figure 7. Representative images of the molecular assembly from Dhakane et al. [48]. (a) Molecular structure for simulation of a case with a bridging molecular layer (30 APTES molecules) at the $\mathrm{LiCoO}_{2}$-polyethylene interface. Hot reservoir (red rectangle on the left) and cold reservoir (blue rectangle on the right) maintained at $350 \mathrm{~K}$ and $250 \mathrm{~K}$ respectively are shown. (b) Schematics of the cathode-APTES interface for simulations with 10, 20, and 30 molecules. 
A two-dimensional electrochemical-thermal coupled model was developed by $\mathrm{Li}$ and Tan [39] for a 38120-type $\mathrm{LiFePO}_{4}$ Li-ion battery. Modeling results showed that the separator thickness strongly impacted battery energy density: the battery energy density dropped from $148.8 \mathrm{~W} \mathrm{~h} / \mathrm{kg}$ to $110.6 \mathrm{~W} \mathrm{~h} / \mathrm{kg}$, while the separator thickness increased from $5 \mu \mathrm{m}$ to $100 \mu \mathrm{m}$. The battery temperature rise and temperature difference dropped when both the separator thermal conductivity and heat capacity increased to $1 \mathrm{~W} \mathrm{~m}^{-1} \mathrm{~K}^{-1}$ and $3500 \mathrm{~J} \mathrm{~kg}^{-1} \mathrm{~K}^{-1}$, respectively.

\subsubsection{Ion Transport}

During the working procedure of the Li-ion batteries, the transportation of ions plays an important role in battery performance. A separator membrane offers ion-conducting routes between electrodes and also electronically isolates the electrodes to prevent internal short-circuit failure, which eventually results in cell fire or explosion [65]. MD simulations have been developed in this area to explore the transport mechanisms and previous numerical studies investigated ion transport in the solid electrolyte [66], cathodes [67], and SEI $[68,69]$. The numerical simulations applied for separators will be reviewed in this section.

Vilčiauskas et al. [42] performed first-principles MD simulations to study proton conductivity at the fundamental molecular level, which represents a first step towards a more detailed understanding of the proton conduction mechanisms in realistic phosphoric acid-based polymer electrolyte materials. The solvation shell characteristics of the H-bond network are significantly over coordinated as compared to those in pure phosphoric acid. However, the lower density of $\mathrm{H}$-bonds slightly increases the local molecular mobilities and artificially increases the proton diffusion coefficient.

$\mathrm{Xu}$ et al. [44] investigated ionic microporous zeolite membranes to overcome the challenge of the trade-off between ion selectivity and conductivity associated with conventional polymeric ion separators. They used the open-source software Packmol to construct the model and applied the LAMMPS package for running the simulations. The proton concentration in the zeolite structure (i.e., $\mathrm{C}_{\mathrm{H}+}$ ) was determined to assist with understanding ion diffusion behaviour in the zeolite pores since the equilibrium values of $\mathrm{C}_{\mathrm{H}+}$ are difficult to measure experimentally. This type of separator showed the ability to drastically reduce the self-discharge rates and enhance energy efficiencies.

Kim et al. [45] demonstrated the effect of the functional groups on the hydronium and hydroxide ions in hydrated poly(ether ether ketone) (PEEK) using MD simulations. The hydronium ion and hydroxide conductivity of the PEEK ion exchange membranes increased as the mole ratio of the functionalized moiety in PEEK increased. The diffusivity of the hydronium and hydroxide ions were calculated using their mean squared displacement in the simulation process via the COMPASS force field.

\subsubsection{Degradation}

The most popular separator materials for Li-ion batteries with organic electrolytes are polyolefin materials [70]. However, the low melting point of polyolefins $\left(135^{\circ} \mathrm{C}\right.$ for $\mathrm{PE}$ and $165^{\circ} \mathrm{C}$ for PP) qualifies their utilization as a thermal fuse to shut down the cell by losing porosity and permeability if an over-temperature condition occurs. The main causes regarding separator degradation are typically traced to the lithium dendrite growth caused by separator pores, attack through the electrolyte, blockage of passageways in the separator over cycling, and structural degradation arising from elevated temperature or high cycle number [71].

A reduced-order capacity-loss model was applied by Jin et al. [29] to improve computational efficiency without sacrificing model fidelity. This model captures the two primary degradation mechanisms that occur in the graphite anode of a typical Li-ion cell: (a) capacity loss due to SEI layer growth, and (b) capacity loss due to isolation of active material. The model matches experimental capacity degradation results within a $20 \%$ error and $2400 \times$ faster than currently existing more complex physically-based electrochemical models. 
Kim et al. [41] studied the formation and growth of SEI for the case of ethylene carbonate (EC), DMC, and mixtures of these electrolytes using molecular dynamics simulations. The simulation studied the distribution of organic and inorganic salts as a function of the distance from the anode surface in Figure 8, and the results show that inorganic salts are found closer to the anode surface while the region near the electrolyte-SEI interface is rich in organic salts.
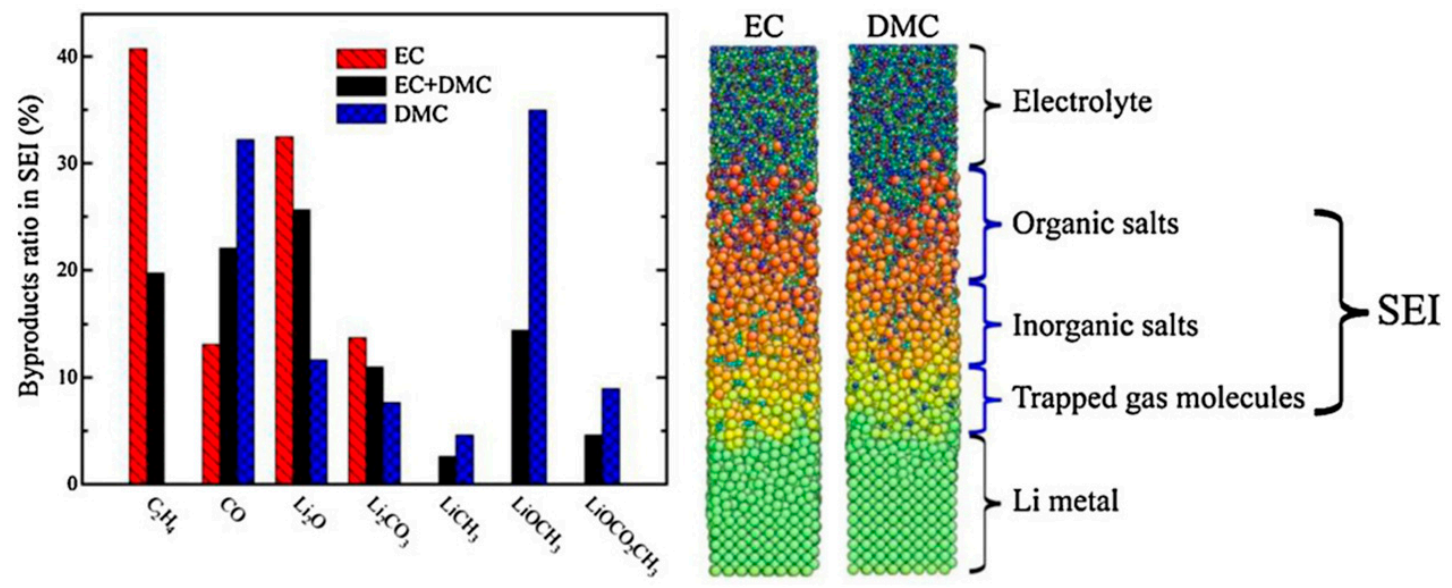

Figure 8. Distribution of the SEI components for different electrolytes (left chart). Atomic configurations from MD simulations; the components of the SEI are identified (right) [41].

\section{Summary and Outlook}

The separator is a crucial component in Li-ion batteries with the function of preventing physical contact between the positive and negative electrodes of the battery and stopping internal short while serving as the electrolyte reservoir to enable ionic transport. The ideal separator should not only have large electrolyte uptake for lowering the cell internal resistance but also have extremely thin thickness with strong mechanical strength, being electrochemically and structurally stable, as well as having a highly porous structure with great tortuosity to prevent the growth of dendritic lithium. In addition, the separator should be able to shut the battery down when overheating occurs for battery safety, as well as being cost-effective through the manufacturing process. However, it is challenging for practical separators to possess these ideal properties simultaneously, and therefore it becomes essential to balance different separator properties to achieve high-performance batteries. Moreover, the safety issue is still another obstacle for the separator and Li-ion battery applications.

In this paper, we have reviewed the recent numerical model advancements for $\mathrm{Li}$-ion battery separators. It included mathematical and mechanical analytical-based simulation approaches such as FEA, CFD, and MD models. Through our summary, numerical simulation can be applied in the investigation of the properties of a separator and the prediction for the performance of the separators. Meanwhile, numerical studies not only provide a time-efficient and cost-effective way but also show a comprehensive understanding of the primary mechanism of the separator performance. Mathematical models describe certain parameters which are not known experimentally and provide the capacity of parameter adjustment. Mechanical models show a detailed microstructure of separators, and combining with FEA and CFD models, the properties of separators can be simulated and predicted. MD models demonstrate a more detailed view of the mechanisms, such as thermal propagation, ion transportation, and degradation. Furthermore, key mechanical design parameters such as Young's modulus and average strain rate for various types of separator materials (i.e., polyolefin, PVDF, PP, PE, Cellulose/lignin, homogeneous solid medium) were analyzed through numerical simulation and characterization approaches. The development of robust, effective numerical tools to address the needs of fire safety of 
separators will be beneficial to the battery industry, providing a complementary design tool for safety engineering design and performance studies.

With the increasing demand of Li-ion batteries with high charge/discharge efficiency and energy density in the future, battery separators with high performances are required for both industrial and research purposes. Currently, the investigation on the separator materials and performances is mainly based on experiments. Numerical simulations can provide reliable results compared to experiments and contribute to study the mechanism of some effects, meanwhile, numerical simulations provide an efficient and economical way to develop the separator and battery system. To provide safer, more functional, and powerful separators, developing a novel Li-ion battery or battery system and optimizing the manufacturing process is critical. The following numerical investigations and development of models are recommended in the future: (i) an effective pre-system failure numerical tool that is able to diagnose the thermal propagation, short-circuiting, separator degradation; (ii) a novel thermal-runaway model for Li-ion battery systems that is able to incorporate multiple battery separator materials with different mechanical and physical properties; (iii) coupling of multi-scale simulation models to study the all-inclusive coupled internal/external phenomena of Li-ion battery fires; and (iv) the simulation findings can be inputted as useful parameters for machine learning algorithms.

Author Contributions: Conceptualization, A.L. and A.C.Y.Y.; methodology, A.L. and W.W.; formal analysis, C.W.; investigation, I.M.D.C.C.; resources, T.B.Y.C.; writing—original draft preparation, A.L.; writing一review and editing, A.C.Y.Y., Q.N.C. and J.Z.; visualization, A.L.; supervision, G.H.Y.; project administration, A.C.Y.Y.; funding acquisition, G.H.Y. All authors have read and agreed to the published version of the manuscript.

Funding: This research was funded by the Australian Research Council (ARC Industrial Transformation Training Centre IC170100032), the Australian Government Research Training Program Scholarship and the Tactical Research Fund, Bushfire and Natural Hazard Cooperative Research Centre in Australia. All financial and technical supports are deeply appreciated by the authors.

Acknowledgments: The author sincerely thank Hu Long for assisting with the image format suggestions.

Conflicts of Interest: The authors declare no conflict of interest.

\section{References}

1. Yoshino, A. The birth of the lithium-ion battery. Angew. Chem. Int. Ed. 2012, 51, 5798-5800. [CrossRef] [PubMed]

2. Etacheri, V.; Marom, R.; Elazari, R.; Salitra, G.; Aurbach, D. Challenges in the development of advanced Li-ion batteries: A review. Energy Environ. Sci. 2011, 4, 3243-3262. [CrossRef]

3. Kong, L.; Li, C.; Jiang, J.; Pecht, M.G. Li-ion battery fire hazards and safety strategies. Energies 2018, 11, 2191. [CrossRef]

4. Ouyang, D.; Chen, M.; Huang, Q.; Weng, J.; Wang, Z.; Wang, J. A review on the thermal hazards of the lithium-ion battery and the corresponding countermeasures. Appl. Sci. 2019, 9, 2483. [CrossRef]

5. Wang, Q.; Mao, B.; Stoliarov, S.I.; Sun, J. A review of lithium ion battery failure mechanisms and fire prevention strategies. Prog. Energy Combust. Sci. 2019, 73, 95-131. [CrossRef]

6. Sun, P.; Bisschop, R.; Niu, H.; Huang, X. A review of battery fires in electric vehicles. Fire Technol. 2020, 56, 1-50. [CrossRef]

7. Huang, X. Separator technologies for lithium-ion batteries. J. Solid State Electrochem. 2011, 15, 649-662. [CrossRef]

8. Lee, H.; Yanilmaz, M.; Toprakci, O.; Fu, K.; Zhang, X. A review of recent developments in membrane separators for rechargeable lithium-ion batteries. Energy Environ. Sci. 2014, 7, 3857-3886. [CrossRef]

9. Deimede, V.; Elmasides, C. Separators for lithium-ion batteries: A review on the production processes and recent developments. Energy Technol. 2015, 3, 453-468. [CrossRef]

10. Lagadec, M.F.; Zahn, R.; Wood, V. Characterization and performance evaluation of lithium-ion battery separators. Nat. Energy 2019, 4, 16-25. [CrossRef]

11. Zhang, H.; Zhou, M.-Y.; Lin, C.-E.; Zhu, B.-K. Progress in polymeric separators for lithium ion batteries. RSC Adv. 2015, 5, 89848-89860. [CrossRef]

12. Cho, J.; Jung, Y.-C.; Lee, Y.S.; Kim, D.-W. High performance separator coated with amino-functionalized $\mathrm{SiO}_{2}$ particles for safety enhanced lithium-ion batteries. J. Membr. Sci. 2017, 535, 151-157. [CrossRef]

13. Liu, J.; Liu, Y.; Yang, W.; Ren, Q.; Li, F.; Huang, Z. Lithium ion battery separator with high performance and high safety enabled by tri-layered SiO2@ PI/m-PE/SiO2@ PI nanofiber composite membrane. J. Power Sources 2018, 396, 265-275. [CrossRef]

14. Wang, S.; Zhang, D.; Shao, Z.; Liu, S. Cellulosic materials-enhanced sandwich structure-like separator via electrospinning towards safer lithium-ion battery. Carbohydr. Polym. 2019, 214, 328-336. [CrossRef] [PubMed] 
15. Fuller, T.F.; Doyle, M.; Newman, J. Simulation and optimization of the dual lithium ion insertion cell. J. Electrochem. Soc. 1994, 141, 1. [CrossRef]

16. Doyle, M.; Newman, J.; Gozdz, A.S.; Schmutz, C.N.; Tarascon, J.M. Comparison of modeling predictions with experimental data from plastic lithium ion cells. J. Electrochem. Soc. 1996, 143, 1890. [CrossRef]

17. Doyle, M.; Fuller, T.F.; Newman, J. Modeling of galvanostatic charge and discharge of the lithium/polymer/insertion cell. J. Electrochem. Soc. 1993, 140, 1526. [CrossRef]

18. Stephenson, D.E.; Hartman, E.M.; Harb, J.N.; Wheeler, D.R. Modeling of particle-particle interactions in porous cathodes for lithium-ion batteries. J. Electrochem. Soc. 2007, 154, A1146. [CrossRef]

19. Thorat, I.V.; Stephenson, D.E.; Zacharias, N.A.; Zaghib, K.; Harb, J.N.; Wheeler, D.R. Quantifying tortuosity in porous Li-ion battery materials. J. Power Sources 2009, 188, 592-600. [CrossRef]

20. Bi, Z. Overview of Finite Element Analysis. In Finite Element Analysis Applications A Systematic and Practical Approach; Katey Birtcher: London, UK, 2018; pp. 1-29.

21. Tu, J.; Yeoh, G.H.; Liu, C. Computational Fluid Dynamics: A Practical Approach; Butterworth-Heinemann: Oxford, UK, 2018.

22. Yuen, A.C.Y.; Chen, T.B.Y.; Yang, W.; Wang, C.; Li, A.; Yeoh, G.H.; Chan, Q.N.; Chan, M.C. Natural ventilated smoke control simulation case study using different settings of smoke vents and curtains in a large Atrium. Fire 2019, 2, 7. [CrossRef]

23. Yuen, A.C.; Yeoh, G.H.; Timchenko, V.; Cheung, S.C.; Chan, Q.N.; Chen, T. On the influences of key modelling constants of large eddy simulations for large-scale compartment fires predictions. Int. J. Comput. Fluid Dyn. 2017, 31, 324-337. [CrossRef]

24. Chen, T.; Yuen, A.; Lin, B.; Liu, L.; Chan, Q.; Zhang, J.; Cheung, S.; Yeoh, G. Characterisation of Pyrolysis Kinetics and Detailed Gas Species Formations of Engineering Polymers via Reactive Molecular Dynamics (ReaxFF). J. Anal. Appl. Pyrolysis 2020, 153, 104931. [CrossRef]

25. Sosso, G.C.; Chen, J.; Cox, S.J.; Fitzner, M.; Pedevilla, P.; Zen, A.; Michaelides, A. Crystal nucleation in liquids: Open questions and future challenges in molecular dynamics simulations. Chem. Rev. 2016, 116, 7078-7116. [CrossRef] [PubMed]

26. Sangha, A.K.; Petridis, L.; Smith, J.C.; Ziebell, A.; Parks, J.M. Molecular simulation as a tool for studying lignin. Environ. Prog. Sustain. Energy 2012, 31, 47-54. [CrossRef]

27. Patel, K.K.; Paulsen, J.M.; Desilvestro, J. Numerical simulation of porous networks in relation to battery electrodes and separators J. Power Sources 2003, 122, 144-152. [CrossRef]

28. Chen-Wiegart, Y.-C.K.; DeMike, R.; Erdonmez, C.; Thornton, K.; Barnett, S.A.; Wang, J. Tortuosity characterization of 3D microstructure at nano-scale for energy storage and conversion materials. J. Power Sources 2014, 249, 349-356. [CrossRef]

29. Jin, X.; Vora, A.; Hoshing, V.; Saha, T.; Shaver, G.; García, R.E.; Wasynczuk, O.; Varigonda, S. Physically-based reduced-order capacity loss model for graphite anodes in Li-ion battery cells. J. Power Sources 2017, 342, 750-761. [CrossRef]

30. Xiao, X.; Wu, W.; Huang, X. A multi-scale approach for the stress analysis of polymeric separators in a lithium-ion battery. J. Power Sources 2010, 195, 7649-7660. [CrossRef]

31. Shi, D.; Xiao, X.; Huang, X.; Kia, H. Modeling stresses in the separator of a pouch lithium-ion cell. J. Power Sources 2011, 196, 8129-8139. [CrossRef]

32. Wu, W.; Xiao, X.; Huang, X.; Yan, S. A multiphysics model for the in situ stress analysis of the separator in a lithium-ion battery cell. Comput. Mater. Sci. 2014, 83, 127-136. [CrossRef]

33. Zhang, X.; Sahraei, E.; Wang, K. Deformation and failure characteristics of four types of lithium-ion battery separators. J. Power Sources 2016, 327, 693-701. [CrossRef]

34. Lagadec, M.F.; Ebner, M.; Zahn, R.; Wood, V. Communication-technique for visualization and quantification of lithium-ion battery separator microstructure. J. Electrochem. Soc. 2016, 163, A992. [CrossRef]

35. Xu, H.; Zhu, M.; Marcicki, J.; Yang, X.G. Mechanical modeling of battery separator based on microstructure image analysis and stochastic characterization. J. Power Sources 2017, 345, 137-145. [CrossRef]

36. Lagadec, M.F.; Zahn, R.; Wood, V. Designing polyolefin separators to minimize the impact of local compressive stresses on lithium ion battery performance. J. Electrochem. Soc. 2018, 165, A1829. [CrossRef]

37. Lagadec, M.F.; Zahn, R.; Müller, S.; Wood, V. Topological and network analysis of lithium ion battery components: The importance of pore space connectivity for cell operation. Energy Environ. Sci. 2018, 11, 3194-3200. [CrossRef]

38. Xu, H.; Bae, C. Stochastic 3D microstructure reconstruction and mechanical modeling of anisotropic battery separators. J. Power Sources 2019, 430, 67-73. [CrossRef]

39. Li, Y.; Tan, Z. Effects of a Separator on the Electrochemical and Thermal Performances of Lithium-Ion Batteries: A Numerical Study. Energy Fuels 2020, 34, 14915-14923. [CrossRef]

40. Parviainen, S.; Djurabekova, F.; Timko, H.; Nordlund, K. Electronic processes in molecular dynamics simulations of nanoscale metal tips under electric fields. Comput. Mater. Sci. 2011, 50, 2075-2079. [CrossRef]

41. Kim, S.-P.; Van Duin, A.C.; Shenoy, V.B. Effect of electrolytes on the structure and evolution of the solid electrolyte interphase (SEI) in Li-ion batteries: A molecular dynamics study. J. Power Sources 2011, 196, 8590-8597. [CrossRef]

42. Vilčiauskas, L.; Tuckerman, M.E.; Melchior, J.P.; Bester, G.; Kreuer, K.-D. First principles molecular dynamics study of proton dynamics and transport in phosphoric acid/imidazole (2:1) system. Solid State Ion. 2013, 252, 34-39. [CrossRef]

43. Yan, S.; Xiao, X.; Huang, X.; Li, X.; Qi, Y. Unveiling the environment-dependent mechanical properties of porous polypropylene separators. Polymer 2014, 55, 6282-6292. [CrossRef] 
44. Xu, Z.; Michos, I.; Cao, Z.; Jing, W.; Gu, X.; Hinkle, K.; Murad, S.; Dong, J. Proton-selective ion transport in ZSM-5 zeolite membrane. J. Phys. Chem. C 2016, 120, 26386-26392. [CrossRef]

45. Kim, D.J.; Park, C.H.; Nam, S.Y. Molecular dynamics simulations of modified PEEK polymeric membrane for fuel cell application. Int. J. Hydrog. Energy 2016, 41, 7641-7648. [CrossRef]

46. Kawagoe, Y.; Surblys, D.; Kikugawa, G.; Ohara, T. Molecular dynamics study on thermal energy transfer in bulk polyacrylic acid. Aip Adv. 2019, 9, 025302. [CrossRef]

47. Xie, W.; Dang, Y.; Wu, L.; Liu, W.; Tang, A.; Luo, Y. Experimental and molecular simulating study on promoting electrolyteimmersed mechanical properties of cellulose/lignin separator for lithium-ion battery. Polym. Test. 2020, 90, 106773. [CrossRef]

48. Dhakane, A.; Varshney, V.; Liu, J.; Heinz, H.; Jain, A. Molecular dynamics simulations of separator-cathode interfacial thermal transport in a Li-ion cell. Surf. Interfaces 2020, 21, 100674. [CrossRef]

49. Xiang, Y.; Li, J.; Lei, J.; Liu, D.; Xie, Z.; Qu, D.; Li, K.; Deng, T.; Tang, H. Advanced separators for lithium-ion and lithium-sulfur batteries: A review of recent progress. ChemSusChem 2016, 9, 3023-3039. [CrossRef]

50. Ihm, D.; Noh, J.; Kim, J. Effect of polymer blending and drawing conditions on properties of polyethylene separator prepared for Li-ion secondary battery. J. Power Sources 2002, 109, 388-393. [CrossRef]

51. Nyman, A.; Behm, M.; Lindbergh, G. Electrochemical characterisation and modelling of the mass transport phenomena in LiPF6-EC-EMC electrolyte. Electrochim. Acta 2008, 53, 6356-6365. [CrossRef]

52. Wu, W.; Xiao, X.; Shi, D. Heat Transfer and Thermal Stress in a Lithium-Ion Battery. In Proceedings of the ASME International Mechanical Engineering Congress and Exposition, Vancouver, BC, Canada, 12-18 November 2010; pp. 343-351.

53. Sheidaei, A.; Xiao, X.; Huang, X.; Hitt, J. Mechanical behavior of a battery separator in electrolyte solutions. J. Power Sources 2011, 196, 8728-8734. [CrossRef]

54. Bulla, M.; Kolling, S.; Sahraei, E. An Experimental and Computational Study on the Orthotropic Failure of Separators for Lithium-Ion Batteries. Energies 2020, 13, 4399. [CrossRef]

55. Pan, Z.; Zhu, J.; Xu, H.; Sedlatschek, T.; Zhang, X.; Li, W.; Gao, T.; Xia, Y.; Wierzbicki, T. Microstructural deformation patterns of a highly orthotropic polypropylene separator of lithium-ion batteries: Mechanism, model, and theory. Extrem. Mech. Lett. 2020, 37, 100705. [CrossRef]

56. Balakrishnan, P.; Ramesh, R.; Kumar, T.P. Safety mechanisms in lithium-ion batteries. J. Power Sources 2006, 155, 401-414. [CrossRef]

57. Shah, K.; Vishwakarma, V.; Jain, A. Measurement of multiscale thermal transport phenomena in Li-ion cells: A review. J. Electrochem. Energy Convers. Storage 2016, 13, 030801. [CrossRef]

58. Bandhauer, T.M.; Garimella, S.; Fuller, T.F. A critical review of thermal issues in lithium-ion batteries. J. Electrochem. Soc. 2011, 158, R1. [CrossRef]

59. Wang, X.; Zhang, J.; Chen, Y.; Chan, P.K. Investigation of interfacial thermal transport across graphene and an organic semiconductor using molecular dynamics simulations. Phys. Chem. Chem. Phys. 2017, 19, 15933-15941. [CrossRef]

60. Feng, T.; Zhong, Y.; Shi, J.; Ruan, X. Unexpected high inelastic phonon transport across solid-solid interface: Modal nonequilibrium molecular dynamics simulations and Landauer analysis. Phys. Rev. B 2019, 99, 045301. [CrossRef]

61. Zhang, J.; Hong, Y.; Tong, Z.; Xiao, Z.; Bao, H.; Yue, Y. Molecular dynamics study of interfacial thermal transport between silicene and substrates. Phys. Chem. Chem. Phys. 2015, 17, 23704-23710. [CrossRef]

62. Zhang, Y.-Y.; Pei, Q.-X.; Mai, Y.-W.; Lai, S.-K. Interfacial thermal conductance in multilayer graphene/phosphorene heterostructure. J. Phys. D Appl. Phys. 2016, 49, 465301. [CrossRef]

63. Meng, H.; Yu, X.; Feng, H.; Xue, Z.; Yang, N. Superior thermal conductivity of poly (ethylene oxide) for solid-state electrolytes: A molecular dynamics study. Int. J. Heat Mass Transf. 2019, 137, 1241-1246. [CrossRef]

64. Bedoya-Martinez, O.; Barrat, J.-L.; Rodney, D. Computation of the thermal conductivity using methods based on classical and quantum molecular dynamics. Phys. Rev. B 2014, 89, 014303. [CrossRef]

65. Oh, Y.S.; Jung, G.Y.; Kim, J.H.; Kim, J.H.; Kim, S.H.; Kwak, S.K.; Lee, S.Y. Janus-Faced, Dual-Conductive/Chemically Active Battery Separator Membranes. Adv. Funct. Mater. 2016, 26, 7074-7083. [CrossRef]

66. Borodin, O.; Smith, G.D. Mechanism of ion transport in amorphous poly (ethylene oxide)/LiTFSI from molecular dynamics simulations. Macromolecules 2006, 39, 1620-1629. [CrossRef]

67. Li, L.; Pascal, T.A.; Connell, J.G.; Fan, F.Y.; Meckler, S.M.; Ma, L.; Chiang, Y.-M.; Prendergast, D.; Helms, B.A. Molecular understanding of polyelectrolyte binders that actively regulate ion transport in sulfur cathodes. Nat. Commun. 2017, 8, 1-10. [CrossRef] [PubMed]

68. An, S.J.; Li, J.; Daniel, C.; Mohanty, D.; Nagpure, S.; Wood III, D.L. The state of understanding of the lithium-ion-battery graphite solid electrolyte interphase (SEI) and its relationship to formation cycling. Carbon 2016, 105, 52-76. [CrossRef]

69. Wang, A.; Kadam, S.; Li, H.; Shi, S.; Qi, Y. Review on modeling of the anode solid electrolyte interphase (SEI) for lithium-ion batteries. npj Comput. Mater. 2018, 4, 1-26. [CrossRef]

70. Arora, P.; Zhang, Z. Battery separators. Chem. Rev. 2004, 104, 4419-4462. [CrossRef]

71. Kabir, M.; Demirocak, D.E. Degradation mechanisms in Li-ion batteries: A state-of-the-art review. Int. J. Energy Res. 2017, 41, 1963-1986. [CrossRef] 